\title{
Air pollution and subclinical airway inflammation in the SALIA cohort study
}

\author{
Mohammad Vossoughi ${ }^{*}$, Tamara Schikowski ${ }^{1,2,3}$, Andrea Vierkötter ${ }^{1}$, Dorothea Sugiri ${ }^{1}$, Barbara Hoffmann ${ }^{1,8}$, \\ Tom Teichert ${ }^{4}$, Christian Herder ${ }^{4,5}$, Thomas Schulte ${ }^{6}$, Christian Luckhaus', Monika Raulf-Heimsoth7, \\ Swaantje Casjens ${ }^{7}$, Thomas Brüning ${ }^{7}$ and Ursula Krämer ${ }^{1}$
}

\begin{abstract}
Background: The association between long-term exposure to air pollution and local inflammation in the lung has rarely been investigated in the general population of elderly subjects before. We investigated this association in a population-based cohort of elderly women from Germany.

Methods: In a follow-up examination of the SALIA cohort study in 2008/2009, 402 women aged 68 to 79 years from the Ruhr Area and Borken (Germany) were clinically examined. Inflammatory markers were determined in exhaled breath condensate (EBC) and in induced sputum (IS). We used traffic indicators and measured air pollutants at single monitoring stations in the study area to assess individual traffic exposure and long-term air pollution background exposure. Additionally long-term residential exposure to air pollution was estimated using land-use regression (LUR) models. We applied multiple logistic and linear regression analyses adjusted for age, indoor mould, smoking, passive smoking and socio-economic status and additionally conducted sensitivity analyses.

Results: Inflammatory markers showed a high variability between the individuals and were higher with higher exposure to air pollution. NO derivatives, leukotriene (LT) $B_{4}$ and tumour necrosis factor-a (TNF-a) showed the strongest associations. An increase of $9.42 \mu \mathrm{g} / \mathrm{m}^{3}$ (interquartile range) in LUR modelled $\mathrm{NO}_{2}$ was associated with measureable $\mathrm{LTB}_{4}$ level (level with values above the detection limit) in $\mathrm{EBC}$ (odds ratio: 1.38, 95\% Cl: 1.02 -1.86) as well as with $\mathrm{LTB}_{4}$ in IS (\%-change: 19\%, 95\% Cl: 7\% - 32\%). The results remained consistent after exclusion of subpopulations with risk factors for inflammation (smoking, respiratory diseases, mould infestation) and after extension of models with additional adjustment for season of examination, mass of IS and urban/rural living as sensitivity analyses.
\end{abstract}

Conclusions: In this analysis of the SALIA study we found that long-term exposure to air pollutants from traffic and industrial sources was associated with an increase of several inflammatory markers in EBC and in IS. We conclude that long-term exposure to air pollution might lead to changes in the inflammatory marker profile in the lower airways in an elderly female population.

Keywords: Particle exposure, Epidemiology, Inflammatory markers, Induced sputum, Exhaled breath condensate

\footnotetext{
* Correspondence: Mohammad.Vossoughi@|UF-Duesseldorf.de

'IUF - Leibniz Research Institute for Environmental Medicine, Auf'm

Hennekamp 50, Düsseldorf 40225, Germany

Full list of author information is available at the end of the article
} 


\section{Background}

It has been hypothesised that air pollution induced subclinical lung inflammation leads to a release of stress signals and of humoral mediators in the airways, which can spill over into the circulation and then contribute to functional impairment and ageing of other tissues and organs [1]. The first step of this cascade however, the association between long-term air pollution and subclinical inflammation of the airways, has rarely been investigated in the general elderly population so far. In a group of elderly subjects in Steubenville, Ohio, it could be shown that shortterm exposure to $\mathrm{PM}_{2.5}$ may lead to airway inflammation as measured by the fraction of exhaled nitric oxide [2]. There are a few studies on susceptible or highly exposed cohorts. For example, in a group of waste handlers, daily exposure to bioaerosols over a short period of time increased the number of neutrophils and induced the secretion of interleukin (IL)-8 in the lower airways [3]. In a population of traffic policemen chronically exposed to traffic-related air pollution a statistically increased neutrophil cell count could be shown compared to a control group of healthy subjects without any exposure to trafficrelated pollutants [4]. In a further investigation, living close to a major road was associated with neutrophilic bronchitis, asthma and decreased lung function in patients with airway diseases [5].

There is evidence that air pollution can induce a subsequent systemic inflammatory response. Alveolar macrophages play an important role in the association between the inflammatory process in the lung and the systemic inflammation because these cells are responsible for ingesting and clearing inhaled pollutants [1]. The interaction of macrophages with particulate matter leads to the increase of their phagocytic activity, oxidant production and release of other inflammatory markers such as tumour necrosis factor- $\alpha$ (TNF- $\alpha)[6,7]$. However, other cells are also able to produce these mediators [1]. Additionally, it has been shown that a range of inhaled substances stimulate alveolar macrophages to produce proinflammatory cytokines such as IL-1, IL-6, and IL-8 and TNF- $\alpha$ [8-11]. Salvi et al. [12] showed a significant increase in neutrophils obtained from bronchial biopsies and also from peripheral blood $6 \mathrm{~h}$ after a short-term $(1 \mathrm{~h})$ exposure to diesel exhaust in a group of healthy volunteers. We are faced with a temporal association between air pollution, various markers of airway inflammation and subclinical inflammation. We aim to investigate the effect of both particulate matter (PM) and nitrogen dioxide $\left(\mathrm{NO}_{2}\right)$ on a range of correlated inflammatory mediators of airway. Thus, it is of particular interest to assess not only the cell count, but also other inflammatory cytokines, which are induced by cell stimulation.

The above mentioned studies on the association of air pollution and subclinical airway inflammation focused on cohorts of either highly exposed or already diseased and presumably more susceptible subjects. However, the association of long-term exposure to air pollution has rarely been investigated in the general population of elderly women so far. Results from SALIA (Study on the influence of air pollution on lung function, inflammation and ageing), a cohort study of elderly German women, already demonstrated the link between long-term trafficrelated air pollution and cardiovascular mortality [13], mild cognitive impairment [14], impaired glucose regulation [15], incidence of type 2 diabetes [16], accelerated skin ageing [17] and objectively measured chronic obstructive pulmonary disease (COPD) [18]. We hypothesise that in the SALIA study an air pollution-induced subclinical inflammation in the lung results in inflammatory mediators into the blood circulation, causing various downstream comorbidities. The SALIA study offers a good opportunity to investigate subclinical inflammation in the lung in a general population of elderly women. We therefore investigated the first step of this pathway namely the influence of long-term exposure to particulate matter and $\mathrm{NO}_{2}$ from traffic and industry on the level of inflammatory markers in exhaled breath condensate (EBC) and in induced sputum (IS) in a crosssectional analysis including 402 elderly women of the population-based SALIA cohort in 2008/2009.

\section{Methods}

\section{Study design and population}

The SALIA study was initiated in the early 1980 s by the State Government of North-Rhine Westphalia to investigate the health effects of air pollution exposure in women. The study population consists of women from the industrialized Ruhr Area in Germany (Dortmund, Duisburg, Herne, Gelsenkirchen, Essen) and two non-industrialized rural areas north of the Ruhr area (Borken, Dülmen). Men were not recruited because of the high occupational exposure of many men in this area, where coal mining and steel industry constituted the predominant sources of income in the time period before the baseline examination. Between 1985 and 1994 baseline examinations were conducted in 4874 women who were 55 years of age at time of recruitment. In 2006, a follow-up examination was conducted to assess the change in respiratory symptoms after a strong decline in concentrations of ambient air pollutants had taken place in the Ruhr Area. Women from Dülmen and Herne did not participate in the follow-up examination because of organisational restrictions in the local health departments. From 2116 (53\% of surviving participants) women who responded to a self-administered postal questionnaire, 1639 women agreed to participate in further clinical examinations. 834 women from this group underwent a clinical examination at local study centres in 2008/2009. The present analysis is based on the 
first 402 women at the age of about 74 who were subjected to an extended collection of blood samples and analysis of inflammatory markers.

\section{Ethical approval}

The ethical committee of the Ruhr University Bochum had favourably reviewed the SALIA Study in 2006 (Registration number: 2732). All women gave their written informed consent before the investigation.

\section{Air pollution assessment}

We applied GIS (Geographic Information System) for the assessment of exposure. Using address coordinates of the participating women, exposure to fine particles, $\mathrm{NO}_{2}$ and traffic was estimated by three different methods:

First, data from monitoring stations maintained by the State Environment Agency covering the Ruhr area in an 8-km grid were used to reflect medium to large-scale spatial variation in air quality. Accordingly we defined long-term air pollution background exposure as fiveyear means of the years 2003-2007 of $\mathrm{PM}_{10}$ (PM with diameter $\leq 10 \mu \mathrm{m})$ and $\mathrm{NO}_{2}$. For this purpose we used the nearest measurement station to the women's home address.

Second, we used land-use regression (LUR) models and data from a measurement campaign (2008/2009) gained in the framework of the EU-ESCAPE study (European Study of Cohorts for Air Pollution Effects) for the assessment of individual long-term exposure. Concentrations of pollutants were measured at 40 sites for $\mathrm{NO}_{2}$ and 20 sites for air-borne PM in the study area based on fourteen-day samples for each season and site. The validated land-use regression models were used to assign estimated $\mathrm{NO}_{2}$, $\mathrm{PM}_{10}, \mathrm{PM}_{2.5}$ and filter absorbance of $\mathrm{PM}_{2.5}$ (soot) concentrations to each individual's residential address $[19,20]$.

Third, traffic exposure was characterized by (1) the distance of the home address to the next major road, defined as $\geq 10,000$ cars per day, and (2) the daily traffic volume within a 100 meters buffer around the home, calculated as the sum of the products of the number of vehicles from all roads with $\geq 5,000$ cars per day multiplied with the street section length in the $100 \mathrm{~m}$ buffer. Figure 1 shows the monitoring stations maintained by the State Environment Agency and the residential addresses of the participants and the corresponding exposure to the LUR-modelled $\mathrm{PM}_{10}$ and $\mathrm{NO}_{2}$.

\section{Assessment of subclinical inflammation}

All examinations were conducted according to standardized protocols. EBC was collected via "Eco-Screen" (VIASYS; Höchberg, Germany) from the participants. We analysed $\mathrm{pH}$, the mediators leukotriene (LT) $\mathrm{B}_{4}$ and nitrate/nitrite, which reflect inflammation of the airways, and 8-isoprostane prostaglandin $\mathrm{F}_{2 \alpha}$ (8-iso $\mathrm{PGF}_{2 \alpha}$ ), which reflects oxidative stress. Women with acute infections of the respiratory tract were excluded from the examination. The measurement of $\mathrm{pH}$ was done via a $\mathrm{pH}$-electrode. NO derivatives were measured by a colorimetric assay kit from Alexis (Cayman Chemicals; Grünberg, Germany) determining the total nitrate/nitrite concentration with a sensitivity of $5 \mu \mathrm{M}$. $\mathrm{LTB}_{4}$ and 8-iso $\mathrm{PGF}_{2 \alpha}$ were measured by a competitive enzyme immune assay (Assay Design, Ann Arbor, MI, USA).

After conducting the EBC procedure, participants inhaled vaporized isomolar saline solution for 10 minutes and were then asked to provoke coughing. IS was collected and processed according to Raulf-Heimsoth et al. [21] and then analysed for soluble inflammatory mediators and differential cell counts. After centrifugation, the cellfree supernatants were aliquoted, stored at $-80^{\circ} \mathrm{C}$ until further analysis of soluble markers. The cell pellets were re-suspended and eosinophils, macrophages, neutrophils, epithelial cells and the total number of cells as the sum of these cells were determined. For differential cell counts cytospins were prepared, stained and counted by three independent observers. The same method as administered for the EBC examination was done to measure nitrate/ nitrite and $\mathrm{LTB}_{4}$ in IS. IL-8, IL- $1 \beta$ and TNF- $\alpha$ were measured using ELISA technique described in detail in RaulfHeimsoth et al. [21]. The Bradford protein assay was used to determine total protein content. In addition, matrix metalloproteinase-9 (MMP-9) was measured using a monoclonal "sandwich" enzyme immunoassay.

\section{Covariate assessment}

We obtained information about a priori known potentially confounding factors from a standardized interview. We included smoking status (recorded as current, former and never smoking), current passive smoking at home, educational level defined as the maximum years of schooling of the woman or her husband as indicator of socio-economic status (low: less than 10 years, medium: 10 years, high: more than 10 years), age and indoor mould infestation which showed an association with outcomes or exposures. Heating with fossil fuels was selected as potential confounder but not included in the final model because it was neither associated with inflammatory outcomes nor with air pollution.

Additionally we used information about the mass of IS, participant's moving history, urban/rural living, chronic airway diseases (COPD, asthma, and bronchitis) and season of the clinical examination in order to model the associations for subpopulations or with additional covariates as sensitivity analyses.

\section{Statistical methods}

Continuous variables of inflammation showed a skewed distribution and a skewed residual distribution and therefore 


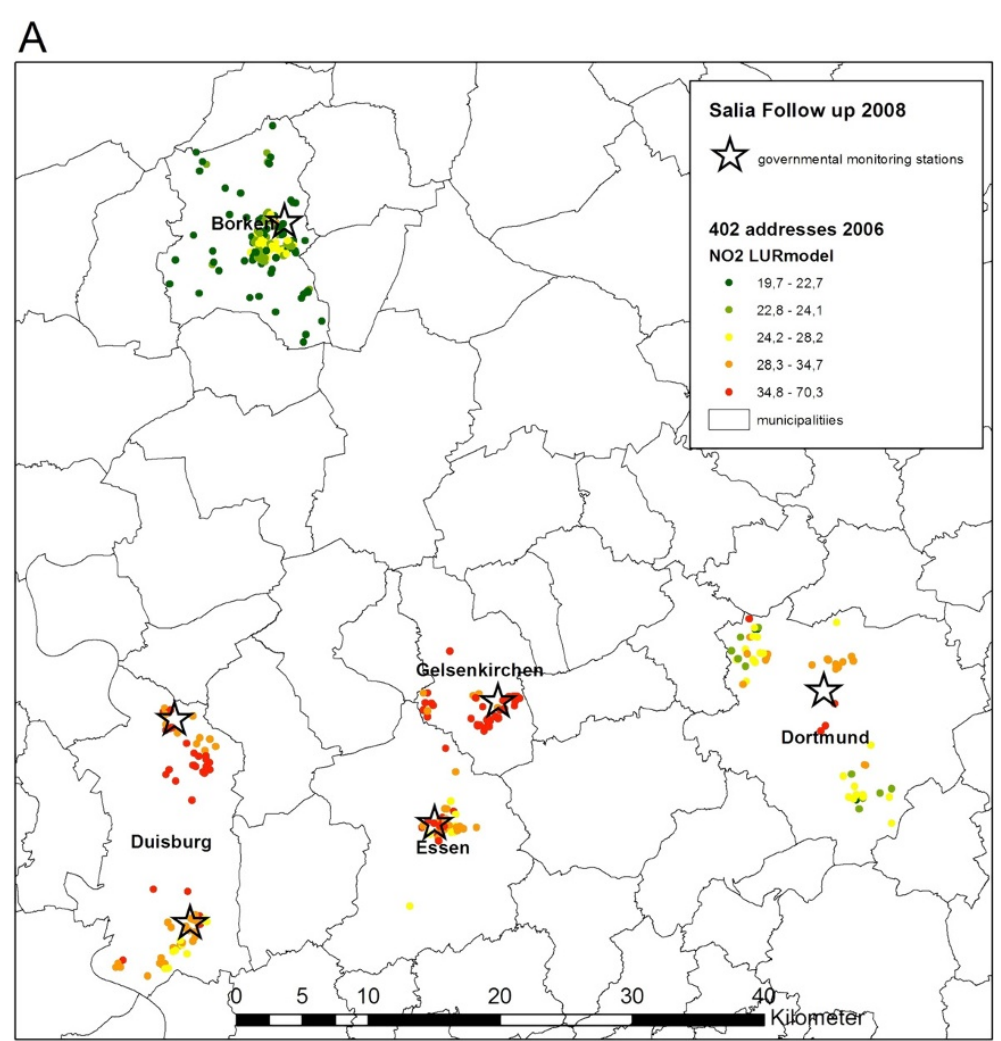

B

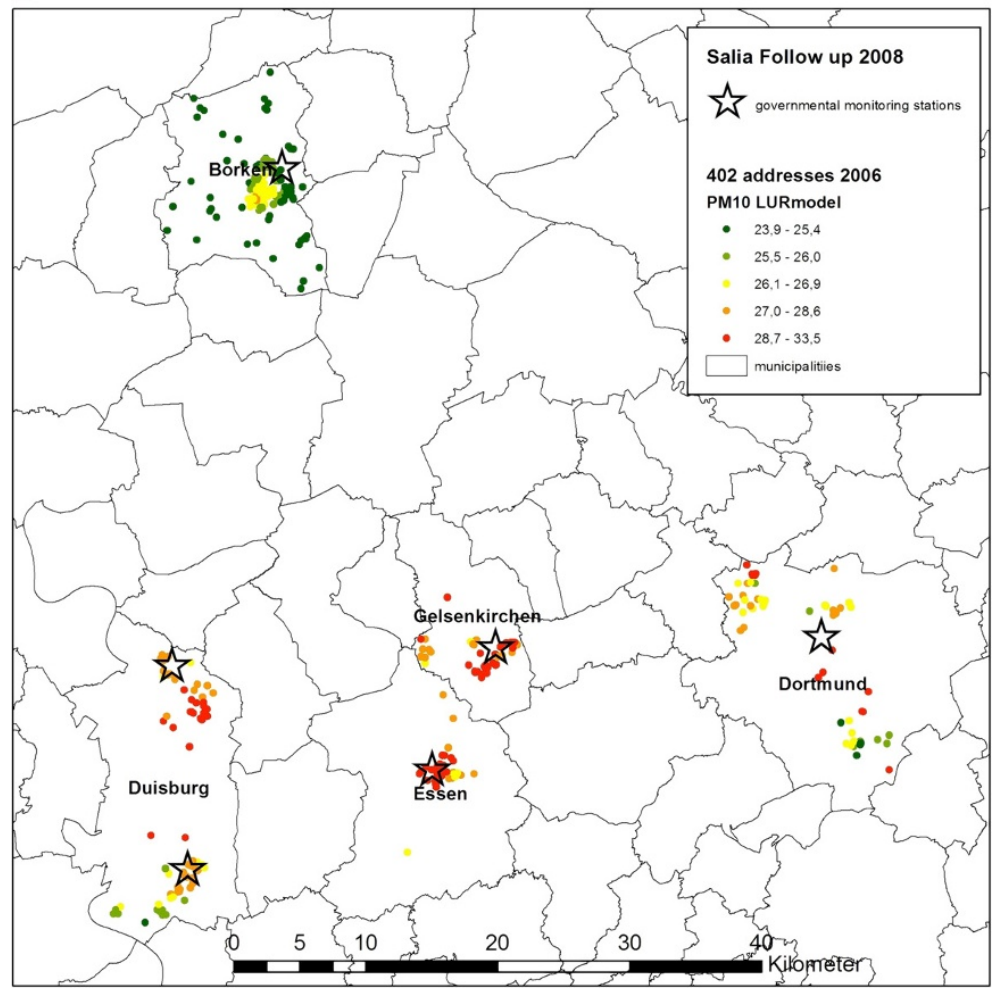

Figure 1 Individual exposure to LUR-modelled $\mathrm{NO}_{2}(\mathrm{~A})$ and $\mathrm{PM}_{10}(\mathrm{~B})$. Monitoring stations maintained by the State Environment Agency and the residential addresses of the participants with the corresponding exposure to the LUR-modelled $\mathrm{NO}_{2}(\mathbf{A})$ and $P M_{10}(\mathbf{B})$ in the urban areas (Dortmund, Gelsenkirchen, Essen, Duisburg) and the rural area (Borken). 
were log-transformed for analysis. If more than $50 \%$ of the values were below the detection limit or equal to zero, continuous variables of inflammation were transformed to binary variables using the detection limit or 0 as cut-off. These were $\mathrm{LTB}_{4}$ in EBC ( $83.3 \%$ below detection limit), and macrophages $(56 \%=0)$ and eosinophils $(77 \%=0)$ in IS. We hypothesise that exposure to air pollution leads to lower $\mathrm{pH}$-values but higher values of other inflammatory markers. Since we expected $\mathrm{pH}$ to be inversely associated with air pollution, $\mathrm{pH}$ was transformed to $9-\mathrm{pH}$ in order to obtain estimates in the same direction comparable with the estimates of other markers of inflammation. "9" was used for this transformation as the highest value for $\mathrm{pH}$ in our dataset. We applied multiple linear or logistic regression analysis to estimate the effect of air pollution and traffic exposure on inflammatory markers. Air pollution concentrations were entered as continuous terms except distance to a major road which was entered in categories (distance < $100 \mathrm{~m}$, distance $\geq 100 \mathrm{~m}$ ). After back-transformation of linear regression coefficients, percentage changes of inflammation variables and the corresponding 95\% confidence intervals $(95 \% \mathrm{CI})$ were presented for an interquartile range (IQR) increase in continuous air pollutants and for the binary variable "living close to major road".

We estimated the associations in crude models (only adjusted for age) and in full models additionally adjusted for smoking status, passive smoking, educational level, exposure to indoor mould and age. The linearity of the exposure-response relationship was investigated via natural spline models in the statistical software $R$ version 2.13.1 (package "splines"). All other statistical analyses were done with SAS version 9.2 (SAS Institute, Cary, $\mathrm{NC}$ ).

\section{Sensitivity analyses}

We investigated whether any effects were due to associations solely observed in specific subgroups of the women. Therefore we repeated the analysis in subgroups and present the effect estimates along with the original estimates in a series of figures. Additionally we included other covariates and tested different definitions of variables. These sensitivity analyses include:

(1) Exclusion of women with indoor mould infestation since mould infestation was already shown in SALIA to be a strong risk factor for the development of inflammatory reactions [22]. (2) Exclusion of currently and formerly smoking women. (3) Exclusion of women with diagnosed asthma or COPD or bronchitis at follow-up of study. (4) Exclusion of women with any change of their residential address since the baseline examination in order to test the stability of results. (5) TNF- $\alpha$ was additionally transformed into binary categories and logistic regression was conducted because just slightly more than $50 \%$ of the values $(55.3 \%)$ were over the detection limit. (6) In an extended model we additionally adjusted for season of the clinical examination. (7) In a separate extended model we used an indicator for urban or rural residential area of women (Ruhr Area vs. Borken) and additionally adjusted the models for this binary variable in order to investigate, whether the estimates change when attaching more weight to the within-area air pollution contrast and whether unmeasured characteristics of rural and urban living confound our estimates. (8) We repeated the analyses with the continuous variable for proximity to the next major road instead of its binary variable in order to avoid information loss due to the dichotomisation. (9) Finally, we adjusted for mass of IS.

\section{Results}

\section{Characteristics of participants}

The characteristics of the 402 participants are shown in Table 1 . The women had a mean age of about 74 (SD = 2.6) years and the majority of them were non-smokers. Women living in urban areas $(\mathrm{N}=212)$ were more frequently smokers $(4.7 \%$ vs. $1.1 \%$ for current smoking, $18.9 \%$ vs. $12.1 \%$ for former smoking) and more often exposed to indoor mould than women in the rural area $(\mathrm{N}=190)(16 \%$ vs. $8.9 \%)$. Distributions of air pollution variables are presented in Table 2. Median levels of all air pollution variables were significantly higher for the urban areas compared to the rural area. The median of daily traffic load from major roads within 100 meters buffer is equal to zero because the majority of women were living further away than 100 meters from the next major road. Women lived on average $3.2 \mathrm{~km}$ (standard deviation $=2.3 \mathrm{~km}$ ) away from the next monitoring station of State Environment Agency. The distributions of markers of inflammation in EBC and IS are presented in Table 3. The geometric means of the concentrations of most inflammatory markers in women from urban area were higher than those from women living in rural areas. These differences are most pronounced for $\mathrm{NO}$ derivatives, TNF- $\alpha$, neutrophils and the total number of cells in sputum.

\section{Results of main analyses}

Figure 2 shows the association between inflammatory markers and individually estimated exposures for an increase by one IQR of air pollutant exposure in the adjusted model. Long-term exposure to modelled $\mathrm{NO}_{2}$ was significantly associated with $\mathrm{LTB}_{4}$ in EBC (odds ratio: 1.38, 95\% CI: 1.02 - 1.86) as well as in IS (\%-change: 19\%, 95\% CI: $7 \%$ - 32\%). Additionally, an increase of $9.42 \mu \mathrm{g} / \mathrm{m}^{3}$ in modelled $\mathrm{NO}_{2}$ (IQR) was associated with a $15.9 \%$ (95\% CI: $1.3 \%$ - 32.6\%) increase in the total number of cells in IS. Modelled $\mathrm{PM}_{10}, \mathrm{PM}_{2.5}$ and $\mathrm{PM}_{2.5}$ absorbance showed the same pattern of effects. For 
Table 1 Characteristics of the study population in rural and in urban areas in 2008/2009

\begin{tabular}{|c|c|c|c|c|}
\hline & Total area $(\mathrm{N}=402)$ & Rural area $(\mathrm{N}=190)$ & Urban area $(\mathrm{N}=212)$ & p-Value ${ }^{a}$ \\
\hline Age (means (sd)) & $74.1(2.6)$ & $74.0(2.5)$ & $74.2(2.6)$ & 0.3259 \\
\hline Years of schooling (\%) & & & & 0.8655 \\
\hline$<10$ & 17.0 & 18.1 & 16.1 & \\
\hline$=10$ & 51.0 & 50.5 & 51.2 & \\
\hline$>10$ & 32.0 & 31.4 & 32.7 & \\
\hline Smoking (\%) & & & & 0.0125 \\
\hline Current & 3.0 & 1.1 & 4.7 & \\
\hline Former & 15.7 & 12.1 & 18.9 & \\
\hline Never & 81.3 & 86.8 & 76.4 & \\
\hline Current passive smoking (\%) & 38.6 & 36.8 & 40.3 & 0.4797 \\
\hline Exposure to indoor mould (\%) & 12.7 & 8.9 & 16.0 & 0.0330 \\
\hline Asthma $^{b}(\%)$ & 9.7 & 8.5 & 10.9 & 0.4214 \\
\hline $\operatorname{COPD}^{\mathrm{b}}(\%)$ & 3.2 & 3.1 & 3.3 & 0.9351 \\
\hline Chronic bronchitis $^{\mathrm{b}}(\%)$ & 11.0 & 11.6 & 10.5 & 0.7109 \\
\hline Change of home address (\%) & 14.2 & 11.1 & 17.0 & 0.0889 \\
\hline
\end{tabular}

${ }^{\mathrm{a}} \mathrm{p}$-Value of $t$-test or Wilcoxon test for the difference of means between rural and urban area.

${ }^{\mathrm{b}}$ Reported as doctor-diagnosed diseases.

example a $2 \mu \mathrm{g} / \mathrm{m}^{3}$ (IQR) increase in $\mathrm{PM}_{2.5}$ was associated with a $16.2 \%(95 \% \mathrm{CI}: 1.1 \%-33.5 \%)$ increase in $\mathrm{NO}$ derivatives in IS. Modelled $\mathrm{PM}_{2.5}$ was also significantly associated with TNF- $\alpha$ (\%-change: $15.8 \%, 95 \%$ CI: $2.6 \%-30.8 \%)$.

Individually estimated traffic volume showed positive associations with inflammatory markers. If traffic volume was increased by one IQR (990 vehicles* $\mathrm{km} / \mathrm{d}$ ), then the chance to have measurable $\mathrm{LTB}_{4}$ was $11 \%$ higher $(95 \% \mathrm{CI}$ : $1.1 \%-21.5 \%)$. In contrast proximity to a major road did not show any consistent pattern of effects with markers of inflammation (Additional file 1: Figure S1).

Long-term exposure as measured at single monitoring stations was also positively associated with the inflammatory

Table 2 Distribution of $\mathrm{PM}, \mathrm{NO}_{2}$ and traffic exposure in rural and in urban areas

\begin{tabular}{|c|c|c|c|c|}
\hline Variable & $\begin{array}{c}\text { Total area }(\mathrm{N}=402) \\
\text { Median }(\mathrm{IQR})\end{array}$ & $\begin{array}{c}\text { Rural area }(\mathrm{N}=190) \\
\text { Median (IQR) }\end{array}$ & $\begin{array}{c}\text { Urban area }(\mathrm{N}=212) \\
\text { Median }(\mathrm{IQR})\end{array}$ & p-Value ${ }^{\mathrm{e}}$ \\
\hline \multicolumn{5}{|c|}{ Nearest monitoring stations (Five-year mean) $^{a}$} \\
\hline $\mathrm{NO}_{2}\left[\mu \mathrm{g} / \mathrm{m}^{3}\right]$ & $30.8(13.2)$ & $20.2(0)$ & $33.4(2.6)$ & $<0.0001$ \\
\hline $\mathrm{PM}_{10}\left[\mu \mathrm{g} / \mathrm{m}^{3}\right]$ & $25.3(3)$ & $25.2(0)$ & $28.2(3.4)$ & $<0.0001$ \\
\hline \multicolumn{5}{|l|}{ LUR-modelled exposure ${ }^{b}$} \\
\hline $\mathrm{NO}_{2}\left[\mu \mathrm{g} / \mathrm{m}^{3}\right]$ & $26.0(9.42)$ & $23.0(2)$ & 31.9 (10.3) & $<0.0001$ \\
\hline $\mathrm{PM}_{10}\left[\mu \mathrm{g} / \mathrm{m}^{3}\right]$ & $26.4(2.26)$ & $25.6(0.89)$ & $27.7(2.7)$ & $<0.0001$ \\
\hline $\mathrm{PM}_{2.5}\left[\mu \mathrm{g} / \mathrm{m}^{3}\right]$ & $17.4(2.06)$ & $17.0(0.42)$ & $18.9(1.7)$ & $<0.0001$ \\
\hline $\mathrm{PM}_{2.5}$ absorbance $\left[10^{-5} \mathrm{~m}^{-1}\right]$ & $1.38(0.44)$ & $1.20(0.13)$ & $1.62(0.47)$ & $<0.0001$ \\
\hline \multirow[t]{2}{*}{ Traffic load ${ }^{\complement}$ [vehicle*km/day] } & 0 (990) & $0(0)$ & 0 (1330) & 0.0003 \\
\hline & $\%$ & $\%$ & $\%$ & \\
\hline Distance $<100 \mathrm{~m}^{\mathrm{d}}$ & 19.1 & 14.7 & 23.1 & $0.0331^{f}$ \\
\hline \multicolumn{5}{|c|}{ 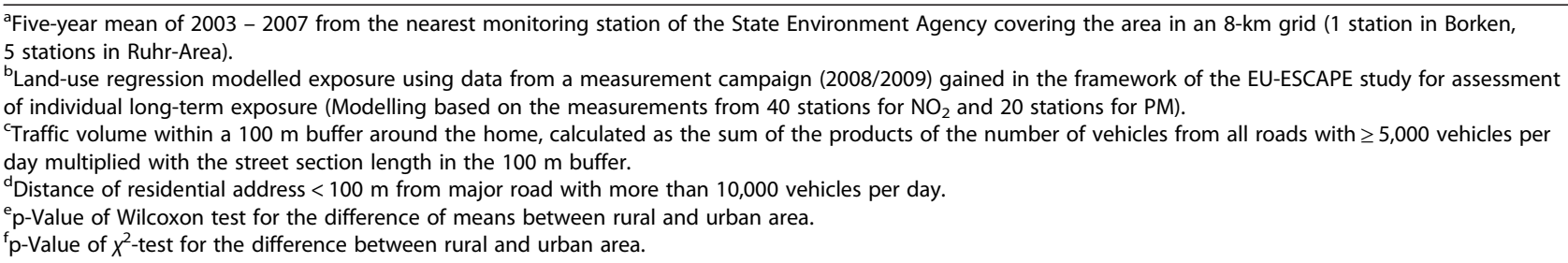 } \\
\hline
\end{tabular}


Table 3 Distribution of inflammatory markers of study population in rural and in urban areas in 2008/2009

\begin{tabular}{|c|c|c|c|c|c|c|c|}
\hline & \multicolumn{2}{|l|}{ Total area } & \multicolumn{2}{|l|}{ Rural area } & \multicolumn{2}{|l|}{ Urban area } & \multirow[t]{2}{*}{$p$-Value ${ }^{b}$} \\
\hline & Geometric mean (gsd) $^{a}$ & $\mathbf{N}$ & Geometric mean (gsd) $^{a}$ & $\mathbf{N}$ & Geometric mean (gsd) $^{a}$ & $\mathbf{N}$ & \\
\hline \multicolumn{8}{|c|}{ Markers in exhaled breath condensate } \\
\hline $\mathrm{pH}$ & $7.1(1.1)$ & 381 & $7.1(1.1)$ & 185 & $7.1(1.1)$ & 196 & 0.854 \\
\hline NO derivatives $[\mu \mathrm{M}]$ & $6.3(1.8)$ & 384 & $6.0(1.8)$ & 186 & $6.6(1.9)$ & 198 & 0.1379 \\
\hline $\mathrm{LTB}_{4}[\mathrm{pg} / \mathrm{mll}]^{\mathrm{e}}$ & $8.9(1.4)$ & 372 & $8.7(1.4)$ & 181 & $9.0(1.4)$ & 191 & 0.2522 \\
\hline 8-iso-PGF 2 a [pg/ml] & $111(1.9)$ & 363 & $112(1.9)$ & 175 & $110(2.0)$ & 188 & 0.8583 \\
\hline \multicolumn{8}{|c|}{ Soluble markers in induced sputum } \\
\hline Total protein content $[\mu \mathrm{g} / \mathrm{ml}]$ & $207(2.1)$ & 324 & $196(2.1)$ & 160 & $219(2.0)$ & 164 & 0.1687 \\
\hline $\mid \mathrm{L}-8[\mathrm{pg} / \mathrm{ml}]^{\mathrm{c}}$ & $974(3.1)$ & 318 & $991(3.2)$ & 158 & 959 (3.0) & 160 & 0.7991 \\
\hline NO derivatives [ $\mu \mathrm{M}]$ & $14.0(2.2)$ & 324 & $12.5(1.9)$ & 160 & $15.8(2.4)$ & 164 & 0.0072 \\
\hline $\mid \mathrm{L}-1 \beta[\mathrm{pg} / \mathrm{ml}]$ & $15.1(2.9)$ & 320 & $15.8(3.1)$ & 159 & $14.5(2.7)$ & 161 & 0.5007 \\
\hline TNF-a [pg/ml] & $1.8(2.0)$ & 320 & $1.6(2.0)$ & 158 & $2.0(2.0)$ & 162 & 0.0067 \\
\hline $\mathrm{LTB}_{4}[\mathrm{pg} / \mathrm{ml}]$ & $642(2.2)$ & 324 & $608(2.1)$ & 160 & $679(2.2)$ & 164 & 0.1988 \\
\hline MMP-9 $[\mathrm{ng} / \mathrm{ml}]^{\mathrm{d}}$ & $94.0(4.5)$ & 279 & $84.0(4.9)$ & 135 & $104(4.2)$ & 144 & 0.2431 \\
\hline \multicolumn{8}{|l|}{ Cells in induced sputum } \\
\hline Total number of cells $\left(\times 10^{5}\right)$ & $14.5(2.7)$ & 324 & $13.0(2.7)$ & 160 & $16.2(2.6)$ & 164 & 0.0433 \\
\hline Macrophages $^{e}$ & $0.1(19.2)$ & 321 & $0.1(18.3)$ & 158 & $0.1(20.3)$ & 163 & 0.4582 \\
\hline Neutrophils $\left(\times 10^{4}\right)^{f}$ & $15.6(6.2)$ & 321 & $12.2(6.4)$ & 158 & $19.8(5.9)$ & 163 & 0.0175 \\
\hline Eosinophils ${ }^{\mathrm{e}}$ & $0.03(9.1)$ & 321 & $0.03(8.0)$ & 158 & $0.04(10.1)$ & 163 & 0.3601 \\
\hline
\end{tabular}

${ }^{\mathrm{a}}$ Geometric standard deviation, ${ }^{\mathrm{b}} \mathrm{p}$-Value of $t$-test for the difference of geometric means between rural and urban area, ${ }^{c}$ Values $>20000$ set to 20000 , ${ }^{d}$ Values $<2$ set to 2, ${ }^{e}$ Transformed to binary variables because for $\mathrm{LTB}_{4}$ in EBC $83.3 \%$ of the values were below the detection limit and for macrophages $56 \%$ and for eosinophils $77 \%$ of the values were equal to zero, ${ }^{f}$ Values $>5 \times 10^{6}$ set to $5 \times 10^{6}$; Values $<1$ set to 1 for the log-transformation.

markers. Five-year mean of $\mathrm{NO}_{2}$ was significantly associated with $\mathrm{LTB}_{4}$ and $\mathrm{NO}$ derivatives in $\mathrm{EBC}$ and with $\mathrm{NO}$ derivatives and TNF- $\alpha$ in IS. Five-year mean of $\mathrm{PM}_{10}$ showed also significant association with $\mathrm{LTB}_{4}$ in EBC (Additional file 1: Figure S1). Air pollution variables showed mostly no associations with concentrations of 8-isoprostane and $\mathrm{pH}$ in EBC, and IL-8 and IL-1 $\beta$ in IS.

We conducted a stratified analysis for co-variables and for urban/rural living. We did not find any effect modification. Especially there was no indication that the effect was stronger in one area compared to the other one (data not shown). The crude associations differed only marginally from the fully adjusted associations (Additional file 1: Figure S2). We did not detect any significant deviations from linearity for the exposure-response associations (data not shown).

\section{Results of sensitivity analyses}

Exclusion of subpopulations or extension of models with additional adjustment for covariables as sensitivity analyses did not change the results relevantly (Additional file 1: Figure S3-S8). Adjustment for urban/rural living attenuated the associations for NO derivatives and TNF- $\alpha$ in sputum and $\mathrm{LTB}_{4}$ in $\mathrm{EBC}$. Estimates were attenuated for modelled $\mathrm{NO}_{2}$ and modelled $\mathrm{PM}_{2.5}$ after adjustment for urban/rural living. (Additional file 1: Figure S9). Effects for TNF- $\alpha$ were in the same direction after transforming the continuous variable into a binary one (Additional file 1: Figure S10). Finally, the associations with distance to major road - modelled as a continuous variable - point into the same direction as the results for the binary variable (Additional file 1: Figure S11).

\section{Discussion}

In this analysis within the SALIA study we found that long-term exposure to air pollutants from traffic and industrial sources was associated with an increase of several inflammatory markers in EBC and in IS. Inflammatory markers showed a high interindividual variability. Amongst others the already known associations between these markers and smoking and mould infestation contributed to this variability [22]. These markers were increased when air pollution was higher. Significant associations of longterm air pollution were shown for $\mathrm{LTB}_{4}$ and NO derivatives in EBC and for total number of cells, NO derivatives, TNF- $\alpha$ and $\mathrm{LTB}_{4}$ in IS. The most consistent associations were found for $\mathrm{LTB}_{4}$ in EBC and changed between 11\% (95\% CI: $1.1 \%$ - 21.5\%) for traffic volume up to $104 \%$ (95\% 

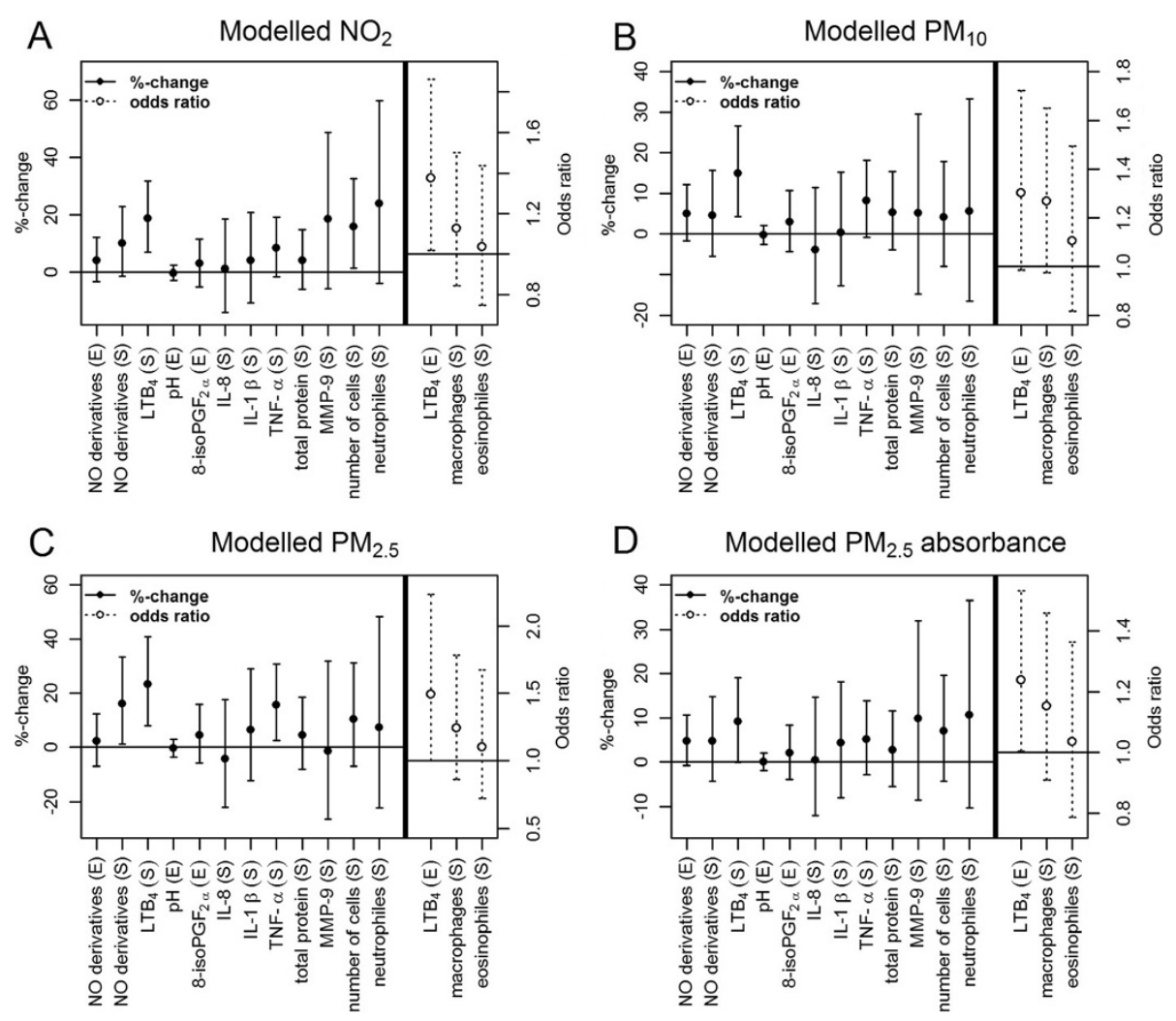

Figure 2 Association of markers of inflammation with particles and $\mathbf{N O}_{2}$. Percentage changes and odds ratios with the corresponding $95 \%$ confidence intervals for inflammatory markers in exhaled breath condensate $(E)^{*}$ and in induced sputum $(S)^{*}$ for an increase by one interquartile range (IQR) of land-use regression modelled $\mathrm{NO}_{2}$ (A), $\mathrm{PM}_{10}$ (B), $\mathrm{PM}_{2.5}$ (C), $\mathrm{PM}_{2.5}$ absorbance (D), adjusted for age, smoking (current smoking, former smoking, never smoking), current passive smoking, indoor mould and socio-economic status by years of schooling. Number of women for each model: NO derivatives $(E)=380, \mathrm{NO}$ derivatives $(\mathrm{S})=320, \mathrm{LTB}_{4}(\mathrm{~S})=320, \mathrm{pH}(\mathrm{E})=377,8$-isoPGF $2 \mathrm{C}(\mathrm{E})=360, \mathrm{IL}-8(\mathrm{~S})=314, \mathrm{IL}-1 \beta(\mathrm{S})=316, \mathrm{TNF}-\mathrm{a}$ $(S)=316$, Total protein $(S)=320$, MMP-9 $(S)=275$, number of cells $(S)=321$, neutrophils $(S)=317, L_{T B}(E)=369$, macrophages $(S)=317$, eosinophils $(S)=317 .{ }^{*}$ Due to place restriction in the figures we did not use the same abbreviations for exhaled breath condensate (EBC) and induced sputum (IS) as stated in the text.

CI: $27.7 \%$ - 226\%) for five-year mean of $\mathrm{NO}_{2}$, respectively. LTB4 is a potent chemoattractant of neutrophils and was shown to contribute significantly to neutrophil influx into the airway in COPD patients [23]. IL-8, IL-1 $\beta, \mathrm{pH}$ and 8 -isoprostane were not associated with air pollution.

Few studies before have investigated long-term exposure to air pollution and markers of local pulmonary inflammation. In patients with COPD, neutrophils, $\mathrm{LTB}_{4}$, IL-8, macrophages, MMP-9 and TNF- $\alpha$ in airways were shown to be increased in several studies [24-28], however little is known about their associations with longterm air pollution in elderly women from the general population. We found a statistically significant association of $\mathrm{PM}_{2.5}$ with $\mathrm{NO}$ derivatives in IS and of the five-year mean $\mathrm{NO}_{2}$ exposure with $\mathrm{NO}$ derivatives in EBC. This observation of an up-regulation of inflammatory activity by long-term exposure to air pollution is supported by a study on elderly subjects in Steubenville,
Ohio, which demonstrated an association between longterm exposure to $\mathrm{PM}_{2.5}$ and the fraction of exhaled nitric oxide (NO) [2].

Modelled long-term $\mathrm{NO}_{2}$ exposure was associated with total cell count in IS, however none of the exposures were clearly associated with neutrophil counts in sputum. This is in contrast to a case-control study on policemen [4], which found a statistically significant increase in the percentage of neutrophils in traffic policemen (median $=65$, $\mathrm{IQR}=13.5$ ) compared to healthy subjects (median $=40.5$, $\mathrm{IQR}=9.5 ; \mathrm{p}<0.01)$ after a long-term exposure to traffic pollutants. Similarly to our study, they did not find any association of air pollutants with eosinophils, although our analysis is based on a binary variable for eosinophils indicating values below or above the detection limit.

Adjustment for urban/rural living attenuated the associations particularly for NO derivatives and TNF- $\alpha$ in sputum and $\mathrm{LTB}_{4}$ in EBC. This might be due to the lack of 
exposure contrasts within the respective areas of residence. We did not include urban/rural living into the main model in order to attach more weight to the between-area air pollution contrast. It is therefore possible, that other, unmeasured characteristics of rural and urban living could have confounded our estimates. Extensive sensitivity analyses with additional covariates however did not yield qualitatively different results.

Schikowski et al. [18] showed that long-term exposure to high concentrations of air pollutants at baseline of the SALIA study were associated with reduced lung function and prevalence of COPD. Therefore it was not clear whether an association of air pollution with local pulmonary inflammatory markers demonstrated a direct effect of current air pollution at follow-up of the SALIA study (2008) or an indirect effect of air pollution at baseline (1985-1994) mediated by a long-lasting effect through established lung diseases with probable inflammation. Therefore we excluded women with diagnosed bronchitis or asthma or COPD. This exclusion did not change our results. Therefore we consider our results as indication of an effect of current air pollution on subclinical pulmonary inflammation.

The strength of the study is that SALIA is a populationbased cohort of elderly women (not a cohort of either highly exposed or diseased and more susceptible subjects) with a detailed exposure assessment and an in-depth characterization of subclinical pulmonary inflammation. We assessed not only the LUR-modelled air pollution but also air pollution at single monitoring stations in order to consider the long-term spatial background air pollution in addition to the individually modelled exposure. Different findings for LUR-modelled and corresponding five-year means of pollutants, which are most pronounced for $\mathrm{LTB}_{4}$ in IS, might be due to the better spatial resolution of the LUR-modelled exposures. Traffic related air pollution is better described with the LUR-models. However, the effects for five-year means of exposures are in the same direction as the effects for LUR-modelled exposure. One limitation of the current study is that our study was based on a subset of the cohort population which attended the follow-up examination in 2008/2009 at a mean age of 74 years. It is therefore possible that the results are attenuated by a healthy survivor effect.

\section{Conclusions}

In this population-based study we could show a crosssectional association between long-term exposure to air pollutants and concentration of several inflammatory markers in fluids collected from the lower respiratory tract in an elderly female population. We conclude that long-term exposure to air pollution might lead to changes in the inflammatory marker profile in the lower airways.

\section{Additional file}

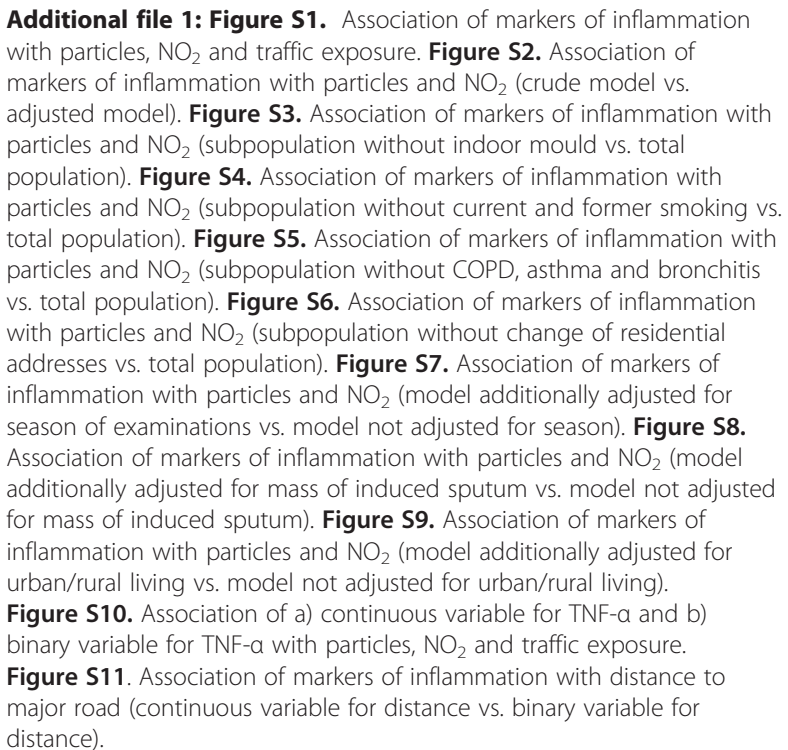

\section{Abbreviations}

COPD: Chronic obstructive pulmonary disease; EBC: Exhaled breath condensate (" $E$ " is used in the figures due to place restriction); ESCAPE: European study of cohorts for air pollution effects; GIS: Geographic information system; IL-1 $\beta$ : Interleukin-1 $\beta$; IL-8: Interleukin-8; IQR: Interquartile range; IS: Induced sputum (" $S$ " is used in the figures due to place restriction); $\mathrm{LTB}_{4}$ : leukotriene $(\mathrm{LT}) \mathrm{B}_{4}$; LUR: Land-use regression; MMP-9: Matrix metalloproteinase-9; $\mathrm{NO}_{2}$ : nitrogen dioxide; OR: Odds ratio; PM: Particulate matter; $\mathrm{PM}_{10}$ : Particulate matter with diameter $\leq 10 \mu \mathrm{m} ; \mathrm{PM}_{2.5}$ : Particulate matter with diameter $\leq 2.5 \mu \mathrm{m}$; SALIA: Study on the influence of air pollution on lung function inflammation and ageing; TNF-a: Tumour necrosis factor-a; 8-iso PGF $_{2 \mathrm{a}}$ : 8-isoprostane prostaglandin $\mathrm{F}_{2 \mathrm{a}}$; $95 \% \mathrm{Cl}$ : $95 \%$ confidence interval.

\section{Competing interests}

The authors report no competing interest.

\section{Authors' contributions}

Study idea and design: UK, TS, AV, MRH. Statistical analysis: MV. Interpretation of results: MV, TS, AV, BH, TT, CH, ThS, CL, MRH, SC, TB, UK. Exposure modelling: DS. Assessment of subclinical inflammation: MRH, SC. All authors participated in manuscript preparation. All authors read and approved the final manuscript.

\section{Acknowledgments}

We would like to thank German Research Foundation (DFG) for supporting this investigation (DFG; HE-4510/2-1, KR 1938/3-1, LU 691/4-1). LUR modelled exposures were provided in the frame of the European ESCAPE study from the European Community's Seventh Framework Program (FP7/2007-2011) under grant agreement number: 211250 . Road maps with emissions from traffic and PM values from monitoring stations were maintained from the State Environmental Agency of North-Rhine Westphalia (LANUV). The German Diabetes Centre is funded by the German Federal Ministry of Health and the Ministry of Innovation, Science and Research of the State of North-Rhine Westphalia. This study was supported in part by a grant from the German Federal Ministry of Education and Research (BMBF) to the German Center for Diabetes Research (DZD e.V.). We would like to thank Dr Thomas Kuhlbusch and Dr Ulrich Quass from Institute for Energy and Environmental Technology (IUTA) for the exposure measurement. We also thank all study participants for the long lasting and continuous participation in the study.

\section{Author details}

${ }^{1}$ IUF - Leibniz Research Institute for Environmental Medicine, Auf'm Hennekamp 50, Düsseldorf 40225, Germany. ${ }^{2}$ Swiss Tropical and Public 
Health Institute, Socinstr. 57, Basel 4002, Switzerland. ${ }^{3}$ University of Basel, Petersplatz 1, Basel 4003, Switzerland. ${ }^{4}$ Institute for Clinical Diabetology, German Diabetes Center, Leibniz Center for Diabetes Research at Heinrich Heine University Düsseldorf, Auf'm Hennekamp 65, Düsseldorf 40225, Germany. ${ }^{5}$ German Center for Diabetes Research (DZD), partner site Düsseldorf, Auf'm Hennekamp 65, Düsseldorf 40225, Germany. ${ }^{6}$ Department of Psychiatry and Psychotherapy, Medical Faculty, Heinrich-Heine-University, Bergische Landstr. 2, Düsseldorf 40629, Germany. ${ }^{7}$ Institute for Prevention and Occupational Medicine of the German Social Accident Insurance, Institute of the Ruhr-Universität Bochum (IPA), Bürkle-de-la-Camp-Platz 1 , Bochum 44789, Germany. ${ }^{8}$ Heinrich Heine University of Düsseldorf, Medical Faculty, Moorenstrasse 5, Düsseldorf 40225, Germany.

Received: 27 September 2013 Accepted: 14 March 2014

Published: 19 March 2014

\section{References}

1. Sinden NJ, Stockley RA: Systemic inflammation and comorbidity in COPD: a result of 'overspill' of inflammatory mediators from the lungs? Review of the evidence. Thorax 2010, 65:930-936.

2. Adamkiewicz G, Ebelt S, Syring M, Slater J, Speizer FE, Schwartz J, Suh H, Gold DR: Association between air pollution exposure and exhaled nitric oxide in an elderly population. Thorax 2004, 59:204-209.

3. Heldal KK, Halstensen AS, Thorn J, Eduard W, Halstensen TS: Airway inflammation in waste handlers exposed to bioaerosols assessed by induced sputum. Eur Respir J 2003, 21:641-645.

4. Dragonieri S, Musti M, Izzo C, Esposito LM, Foschino Barbaro MP, Resta O, Spanevello A: Sputum induced cellularity in a group of traffic policemen. Sci Total Environ 2006, 367:433-436

5. Wallace J, D'silva L, Brannan J, Hargreave FE, Kanaroglou P, Nair P: Association between proximity to major roads and sputum cell counts. Can Respir J 2011, 18:13-18.

6. Becker S, Soukup JM, Gilmour MI, Devlin RB: Stimulation of human and rat alveolar macrophages by urban air particulates: effects on oxidant radical generation and cytokine production. Toxicol Appl Pharmacol 1996, 141:637-648.

7. Goldsmith CA, Imrich A, Danaee H, Ning YY, Kobzik L: Analysis of air pollution particulate-mediated oxidant stress in alveolar macrophages. J Toxicol Environ Health A 1998, 54:529-545.

8. Mukae H, Hogg JC, English D, Vincent R, Van Eeden SF: Phagocytosis of particulate air pollutants by human alveolar macrophages stimulates the bone marrow. Am J Physiol Lung Cell Mol Physiol 2000, 279:L924-L931.

9. Terashima T, Wiggs B, English D, Hogg JC, Van Eeden SF: Phagocytosis of small carbon particles (PM10) by alveolar macrophages stimulates the release of polymorphonuclear leukocytes from bone marrow. Am J Respir Crit Care Med 1997, 155:1441-1447.

10. Terashima T, Klut ME, English D, Hards J, Hogg JC, Van Eeden SF: Cigarette smoking causes sequestration of polymorphonuclear leukocytes released from the bone marrow in lung microvessels. Am J Respir Cell Mol Biol 1999, 20:171-177.

11. Van Eeden SF, Tan WC, Suwa T, Mukae H, Terashima T, Fujii T, Qui D, Vincent R, Hogg JC: Cytokines involved in the systemic inflammatory response induced by exposure to particulate matter air pollutants (PM(10)). Am J Respir Crit Care Med 2001, 164:826-830.

12. Salvi S, Blomberg A, Rudell B, Kelly F, Sandstrom T, Holgate ST, Frew A: Acute inflammatory responses in the airways and peripheral blood after short-term exposure to diesel exhaust in healthy human volunteers. Am J Respir Crit Care Med 1999, 159:702-709.

13. Gehring U, Heinrich J, Krämer U, Grote V, Hochadel M, Sugiri D, Kraft M, Rauchfuss K, Eberwein HG, Wichmann HE: Long-term exposure to ambient air pollution and cardiopulmonary mortality in women. Epidemiology 2006, 17:545-551.

14. Ranft U, Schikowski T, Sugiri D, Krutmann J, Kramer U: Long-term exposure to traffic-related particulate matter impairs cognitive function in the elderly. Environ Res 2009, 109:1004-1011.

15. Teichert T, Vossoughi M, Vierkotter A, Sugiri D, Schikowski T, Schulte T, Roden M, Luckhaus C, Herder C, Kramer U: Association between traffic-related air pollution, subclinical inflammation and impaired glucose metabolism: results from the SALIA study. PLoS One 2013, 8:e83042.

16. Krämer U, Herder C, Sugiri D, Strassburger K, Schikowski T, Ranft U, Rathmann W: Traffic-related Air Pollution and Incident Type 2 Diabetes:
Results from the SALIA Cohort Study. Environ Health Perspect 2010, 118:1273-1279.

17. Vierkotter A, Schikowski T, Ranft U, Sugiri D, Matsui M, Kramer U, Krutmann J: Airborne particle exposure and extrinsic skin aging. J Invest Dermatol 2010, 130:2719-2726.

18. Schikowski T, Sugiri D, Ranft U, Gehring U, Heinrich J, Wichmann HE, Krämer U: Long-term air pollution exposure and living close to busy roads are associated with COPD in women. Respir Res 2005, 6:152-162.

19. Beelen R, Hoek G, Vienneau D, Eeftens M, Dimakopoulou K, Pedeli X, Tsai M-Y, Künzli N, Schikowski T, Marcon A, Eriksen KT, Raaschou-Nielsen O, Stephanou E, Patelarou E, Lanki T, Yli-Tuomi T, Declercq C, Falq G, Stempfelet M, Birk M, Cyrys J, von Klot S, Nádor G, Varró MJ, Dedele A, Grazuleviciene R, Mölter A, Lindley S, Madsen C, Cesaroni G, et al: Development of $\mathrm{NO}_{2}$ and $\mathrm{NO}_{x}$ land use regression models for estimating air pollution exposure in 36 study areas in Europe - The ESCAPE project. Atmos Environ 2013, 72:10-23.

20. Eeftens M, Beelen R, de Hoogh K, Bellander T, Cesaroni G, Cirach M, Declercq C, Dedele A, Dons E, de Nazelle A, Dimakopoulou K, Eriksen K, Falq G, Fischer P, Galassi C, Grazuleviciene R, Heinrich J, Hoffmann B, Jerrett M, Keidel D, Korek M, Lanki T, Lindley S, Madsen C, Mölter A, Nador G, Nieuwenhuijsen M, Nonnemacher M, Pedeli X, Raaschou-Nielsen O, et al: Development of land use regression models for $\mathrm{PM}_{2.5}, \mathrm{PM}_{2.5}$ absorbance, $\mathrm{PM}_{10}$ and $\mathrm{PM}_{\text {coarse }}$ in 20 European study areas;results of the ESCAPE project. Environ Sci Technol 2012, 46:11195-11205.

21. Raulf-Heimsoth M, Pesch B, Kendzia B, Spickenheuer A, Bramer R, Marczynski B, Merget $R$, Bruning T: Irritative effects of vapours and aerosols of bitumen on the airways assessed by non-invasive methods. Arch Toxicol 2011, 85(Suppl 1):S41-S52.

22. Raulf-Heimsoth M, Kespohl S, Pesch B, Sander I, Casjens S, Ranft U, Schikowski T, Harth V, Brüning T, Krämer U: Eignet sich die Bestimmung von Aspergillusversicolor-spezifischen IgG-Antikörpern als Expositionsmarker für Schimmelpilzbefall in Innenräumen? Allergologie 2010, 33:558-561.

23. Crooks SW, Bayley DL, Hill SL, Stockley RA: Bronchial inflammation in acute bacterial exacerbations of chronic bronchitis: the role of leukotriene B4. Eur Respir J 2000, 15:274-280.

24. Liu J, Sandrini A, Thurston MC, Yates DH, Thomas PS: Nitric oxide and exhaled breath nitrite/nitrates in chronic obstructive pulmonary disease patients. Respiration 2007, 74:617-623.

25. Brajer B, Batura-Gabryel H, Nowicka A, Kuznar-Kaminska B, Szczepanik A: Concentration of matrix metalloproteinase- 9 in serum of patients with chronic obstructive pulmonary disease and a degree of airway obstruction and disease progression. J Physiol Pharmacol 2008, 59(Suppl 6):145-152.

26. Larsson K: Inflammatory markers in COPD. Clin Respir J 2008, 2(Suppl 1):84-87.

27. Eickmeier O, Huebner M, Herrmann E, Zissler U, Rosewich M, Baer PC, Buhl R, Schmitt-Grohe S, Zielen S, Schubert R: Sputum biomarker profiles in cystic fibrosis (CF) and chronic obstructive pulmonary disease (COPD) and association between pulmonary function. Cytokine 2010, 50:152-157.

28. Ichinose M: Differences of inflammatory mechanisms in asthma and COPD. Allergol Int 2009, 58:307-313.

doi:10.1186/1742-4933-11-5

Cite this article as: Vossoughi et al:: Air pollution and subclinical airway inflammation in the SALIA cohort study. Immunity \& Ageing 2014 11:5.

\section{Submit your next manuscript to BioMed Central and take full advantage of:}

- Convenient online submission

- Thorough peer review

- No space constraints or color figure charges

- Immediate publication on acceptance

- Inclusion in PubMed, CAS, Scopus and Google Scholar

- Research which is freely available for redistribution 